\title{
Using maleic anhydride functionalized graphene oxide for improving the interfacial properties of carbon fiber/BMI composites
}

\author{
W. Li , Y. Z. Yue, M. Y. Wang, Q. Li, R. Ren
}

Faculty of Aerospace Engineering, Shenyang Aerospace University, Liaoning Key Laboratory of High Performance

Polymer Matrix Composites, 110136 Shenyang, China

Received 11 April 2016; accepted in revised form 16 June 2016

\begin{abstract}
Maleic anhydride functionalized graphene oxide (MAH-GO) was synthesized and then introduced into carbon fiber (CF) reinforced bismaleimide (BMI) composites, with the aim of improving the interfacial adhesion strength between $\mathrm{CF}$ and BMI resin. Various characterization techniques including Fourier transform infrared spectroscopy (FT-IR), X-ray photoelectron spectra (XPS) and thermogravimetric analysis (TGA) demonstrated that the maleic anhydride has been successfully grafted onto the GO surfaces. The study showed that the interlaminar shear strength (ILSS) and flexural properties of CF/BMI composites were all improved by the incorporation of GO and MAH-GO, and the MAH-GO showed the substantially improved effect due to the strong interaction between the MAH-GO and the resin matrix. The maximum increment of the ILSS, flexural strength and flexural modulus of composites were 24.4, 28.7 and 49.7\%, respectively. Scanning electron microscope (SEM) photographs of the fracture surfaces revealed that the interfacial bonding between $\mathrm{CF}$ and resin matrix was significantly strengthened by the addition of MAH-GO. The results suggest that this feasible method may be an ideal substitute for the traditional method in the interfacial modification of composites.
\end{abstract}

Keywords: polymer composites, interfacial bonding, graphene, covalent functionalization, bismaleimide

\section{Introduction}

Carbon fiber (CF) reinforced polymer composites have been widely used in aerospace, automobiles, constructions and other industry fields because of their excellent mechanical properties, such as high specific strength, specific modulus and damping capacity [1-3]. As well known, the mechanical properties of fiber reinforced composites are largely dominated by the fiber-matrix interfacial adhesion. Good interfacial bonding is essential to ensure the load transfer from the matrix to the fiber reinforcements, which is helpful to reduce the stress concentrations and improve the overall mechanical properties of final composite products. However, the fiber-matrix interfacial adhesion tends to be weak since the CFs surfaces are smooth, non-polar and chemical inert $[4,5]$. In order to improve the interfacial bonding properties, a series of effective methods have been successfully developed for surface modification of $\mathrm{CFs}$, such as chemical oxidation, high-energy radiation, grafting, and plasma treatment, etc. [5-8].

Recently, the utility of graphene oxide (GO) or functionalized GO as additives to enhance the interfacial properties of CF reinforced polymer composites has begun to attract more attention $[2,9]$. Because the functionalized $\mathrm{GO}$ has various functional groups and large specific surface area, it can be uniformly dispersed and firmly adsorbed on the surface of CFs to prepare a new hierarchical reinforcement. Therefore, the interfacial adhesion of composites can be im-

$\overline{{ }^{*} \text { Corresponding author, e-mail: } 1 \text { iwei@sau.edu.cn }}$

(C) BME-PT 
proved by this new hierarchical reinforcement due to consuming much more energy by pulling out the functionalized GO from the matrix or breakage of them. On the other hand, the introduction of the functionalized GO can increase the modulus of polymer matrix significantly [10-12], that is to say, it can reduce the modulus difference between matrix and fiber, which is also beneficial for the applied load transferring more effectively from matrix to CFs.

CF reinforced bismaleimide (BMI) composites have been widely used as one of advanced composites owing to their superior mechanical and thermal properties $[13,14]$. Nevertheless, the properties need to be further improved when they are used in some specific environments. Nowadays, GO or functionalized GO have been used for modifying the BMI resin by some researchers. For example, Yan and coworkers [15, 16] grafted hyperbranched polysilane (HBPSi) and hyperbranched polytriazine (HBPT) onto the reduced GO surfaces, respectively. The results revealed that the introduction of HBPSi (or HBPT) functionalized reduced GO could decrease the frictional coefficient and the wear rate of the BMI resin dramatically. Liu et al, [13] reported a 39\% increase in impact strength by adding $0.3 \mathrm{wt} \%$ aniline functionalized graphene nanosheets in BMI resin. Our previous work [17] also found that the suitable addition of silane functionalized GO (MPTS-GO) could significantly improve the mechanical properties of the BMI composites. Although substantial research has pointed out that the addition of graphene into polymer matrix can result in the considerable improvements of new or modified properties, there are few reports to study the effect of graphene on enhancing the properties of $\mathrm{CF} / \mathrm{BMI}$ composites, especially the interfacial adhesion.

Herein, we report the fabrication of a novel covalent functionalized GO by using maleic anhydride. Then the maleic anhydride functionalized GO (MAH-GO) was introduced into the $\mathrm{CF} / \mathrm{BMI}$ composite system to improve the mechanical properties. Because the carbon-carbon bond of maleic anhydride is high reactive activity, the MAH-GO is easy to participate in the curing reaction of BMI resin, and thus improving its dispersibility and strengthening the interaction with the resin. The aim of the current investigation is to determine the role of MAH-GO on the interfacial adhesion of $\mathrm{CF} / \mathrm{BMI}$ composites.

\section{Experimental section}

\subsection{Materials}

The BMI resin used was the 4,4'-bismaleimide diphenyl methane (BDM) modified with the $\mathrm{O}, \mathrm{O}^{\prime}$ diallyl bisphenol A (DBA). BDM and DBA were both supplied by Honghu New Materials Technical Co. LTD., China. Unidirectional carbon fiber (T700SC-12k, diameter: $7 \mu \mathrm{m}$ ) was purchased from Toray Industries, Inc., Japan. Pristine graphite powder was obtained from Qingdao Jinrilai Graphite Co., Ltd., China. Maleic anhydride (MAH), ethanol, acetone, and dimethylformamide (DMF) were of analytical grade and obtained from Sinopram Chemical Reagent Co., Ltd., China.

\subsection{Fabrication of GO and MAH functionalized GO (MAH-GO)}

GO was prepared by oxidizing natural graphite powder based on a modified Hummers method [17, 18]. To functionalize GO, $0.5 \mathrm{~g}$ GO was placed in a $250 \mathrm{~mL}$ dried beaker with $100 \mathrm{~mL}$ DMF and sonicated for $1 \mathrm{~h}$ to form a homogeneous solution. $15 \mathrm{~g}$ MAH was then added into the mixture solution and transferred into a three-necked flask with refluxing at $80^{\circ} \mathrm{C}$ for $1 \mathrm{~h}$. After the reaction finished, the product was washed with ethanol several times to remove all the unreacted MAH. The solid was finally dried under vacuum to obtain the MAH-GO. The preparation process of MAH-GO is shown in Figure 1.

\subsection{Fabrication of $\mathrm{CF}$ reinforced BMI composites}

According to the different weight ratios, the MAHGO was firstly added into $100 \mathrm{~mL}$ ethanol and sonicated for $1 \mathrm{~h}$ to promote its dispersion. $51 \mathrm{~g}$ DBA was then added into the ethanol solutions and sonicated for another $1 \mathrm{~h}$. In order to remove all the ethanol, the mixture container was transferred into an oil bath and distilled according to the scheduled process: $80^{\circ} \mathrm{C}$ for $1 \mathrm{~h}, 100^{\circ} \mathrm{C}$ for $2 \mathrm{~h}, 120^{\circ} \mathrm{C}$ for $1 \mathrm{~h}$, and $140^{\circ} \mathrm{C}$ for $6 \mathrm{~h}$. Then, $68 \mathrm{~g}$ BDM was added to the mixture, and this was followed by prepolymerization for $30 \mathrm{~min}$ at $140{ }^{\circ} \mathrm{C}$. The molar ratio of DBA to BDM was 0.87:1. $150 \mathrm{~mL}$ acetone was added into the resultant prepolymer under refluxing for $1 \mathrm{~h}$ to obtain a homogenous thin resin solution. The unidirectional CF was impregnated by passing through this resin solution. Two glass bars were used to scrape off excess 

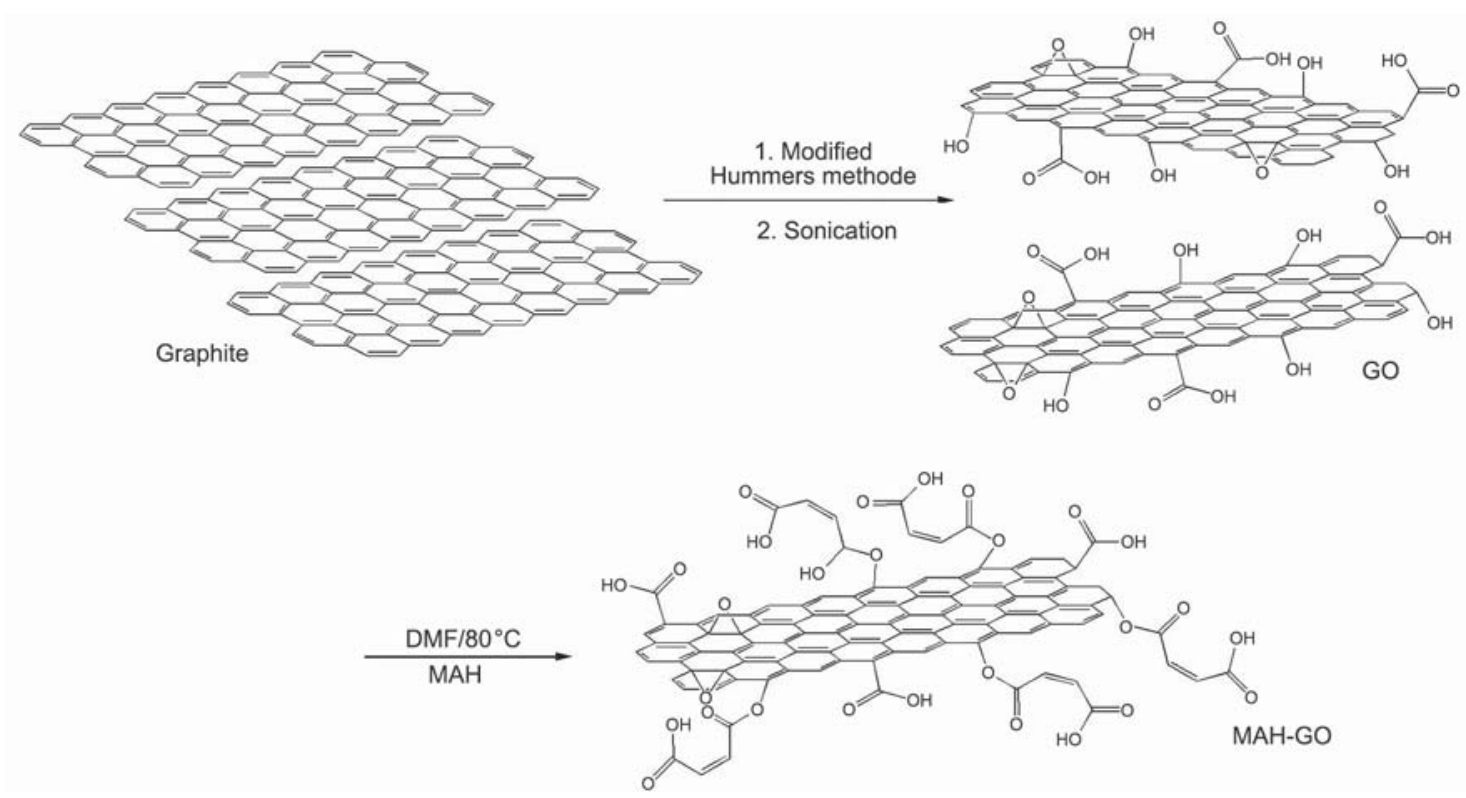

Figure 1. Schematic of preparation process of MAH-GO

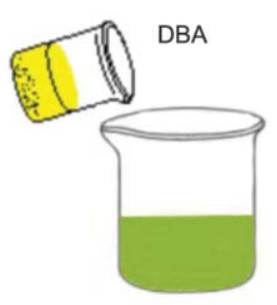

Ethanol solution of MAH-GO

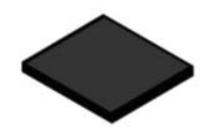

Composite samples
1. Ultrasonic processing

2. Remove ethanol

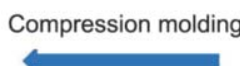

rar

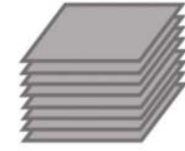

Prepreg

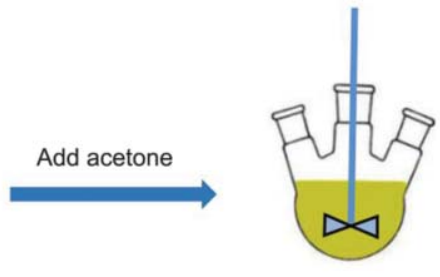

Resin solution

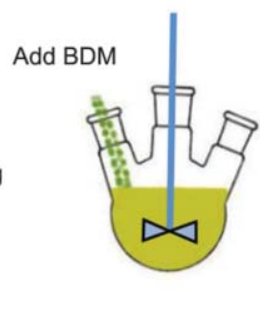

Stiring

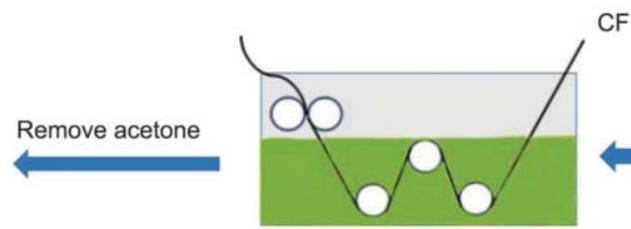

Impregnation

Figure 2. Fabrication process of $\mathrm{CF} / \mathrm{MAH}-\mathrm{GO} / \mathrm{BMI}$ composites

resin solution from the CF carefully, and then the solvent was removed in a vacuum oven at $80^{\circ} \mathrm{C}$ to obtain the prepregs. The composites were prepared by using compression molding method. The preparation procedure of CF composites is represented in Figure 2. The referential $\mathrm{CF} / \mathrm{GO} / \mathrm{BMI}$ composites were also prepared in the same procedure.

\subsection{Characterization}

Transmission electron microscopy (TEM) micrographs were used to observe the morphologies of GO and MAH-GO sheets by using a TEM instrument (TecnaiG220, FEI, USA). The sheets were firstly dis- persed in de-ionized water by sonication for $30 \mathrm{~min}$ and then some pieces were collected on carbon-coated copper grids for TEM observation.

Fourier transform infrared (FT-IR) spectra were recorded on a spectrometer (Spectrum 100, Perkin Elmer, USA) using $\mathrm{KBr}$ pellets at room temperature. The frequency range of FT-IR was $4000-400 \mathrm{~cm}^{-1}$. $\mathrm{X}$-ray photoelectron spectroscopy (XPS) measurements were used to determine the surface groups of GO and MAH-GO by using an XPS instrument (ESCALAB 250, Thermo, USA). The nonlinear least squares fitting (NLLSF) program with a GaussianLorentzian production function was used for curve 
fitting of $\mathrm{C} 1 \mathrm{~s}$ spectra. The surface chemical composition was calculated from the areas of relevant spectra peaks.

Thermogravimetric analysis (TGA) were measured under a nitrogen atmosphere from 60 to $700^{\circ}$ with a thermal analyzer (TGA-7, Perkin Elmer, USA) at a heating rate of $10^{\circ} \mathrm{C} \cdot \mathrm{min}^{-1}$.

Scanning electron microscopy (SEM) observations were conducted with a scanning electron microscope ( IGMA, Carl Zeiss, Germany). Each sample was coated with gold prior to SEM observation.

The interlaminar shear strength (ILSS) of CF composites was carried out by the short beam three point bending test on a universal testing machine (WOW 1000, Jinan Shidai Shijin Testing machine Group Co., Ltd., China) according to the ASTM D2344. The cross-head speed was $2 \mathrm{~mm} \cdot \mathrm{min}^{-1}$. The width of test specimen was $6 \mathrm{~mm}$ and the thickness was $2.4 \mathrm{~mm}$. A span-to-depth ratio of 5:1 was used.

The flexural properties of composites specimens were carried out using three-point bending mode on the above mentioned WOW 1000 testing machine according to ASTM D-790. The crosshead rate was $2 \mathrm{~mm} \cdot \mathrm{min}^{-1}$. The length between supports span was 16 times the depth of test specimen. At least seven samples were tested in each experiment and the average value was reported.

\section{Results and discussion}

\subsection{Characterization of GO and MAH-GO}

TEM micrographs of the GO and MAH-GO sheets are given in Figure 3. The GO and MAH-GO sheets show almost similar structures with a few thin ripples in their surfaces. FT-IR, XPS and TGA analysis were used to testify the surface functionalization of

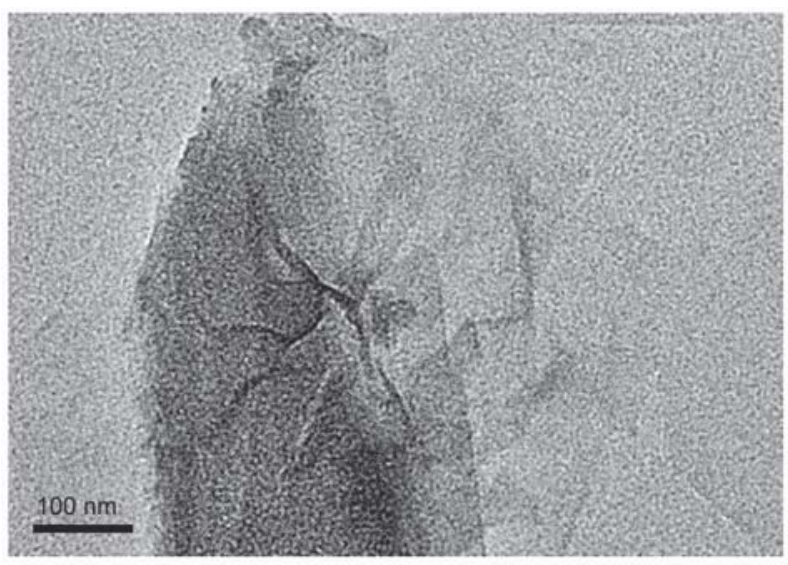

a)

Figure 3. TEM images of (a) GO and (b) MAH-GO

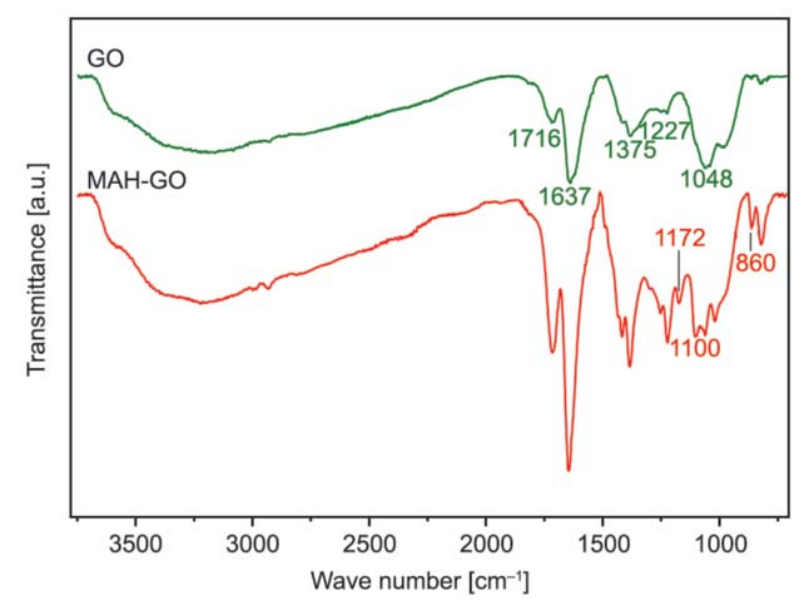

Figure 4. FT-IR spectra of GO and MAH-GO

GO. Figure 4 illustrates a comparison of FT-IR spectra of GO and MAH-GO. In the case of GO, the peak located at 1716, 1637, 1375, 1227 and $1048 \mathrm{~cm}^{-1}$ are assigned to the stretching vibrations of $\mathrm{C}=\mathrm{O}$ of carboxylic and carbonyl groups, $\mathrm{C}=\mathrm{C},-\mathrm{OH}$ of the carboxyl group, $\mathrm{C}-\mathrm{O}$ of the epoxy group and $\mathrm{C}-\mathrm{OH}$ group, respectively. Similar patterns were observed in other studies $[10,19]$. These observations indicate that the GO contains abundant oxygen-containing functional groups. After surface covalent functionalization, the bands at 1716, 1637 and $1375 \mathrm{~cm}^{-1}$ became stronger. Meanwhile, the new band appeared at $860 \mathrm{~cm}^{-1}$, correspond to the in-plane bending vibration of $\mathrm{C}-\mathrm{H}$ of $\mathrm{CH}=\mathrm{CH}$ group. Another two new bands at 1100 and $1172 \mathrm{~cm}^{-1}$ are assigned to the stretching vibration of $\mathrm{C}-\mathrm{O}$ of the ester group. The appearance of ester group clearly implies that the MAH molecules were reacted with the electrophilic groups of the GO surfaces, which provided more evidence for this successful chemical functionalization.

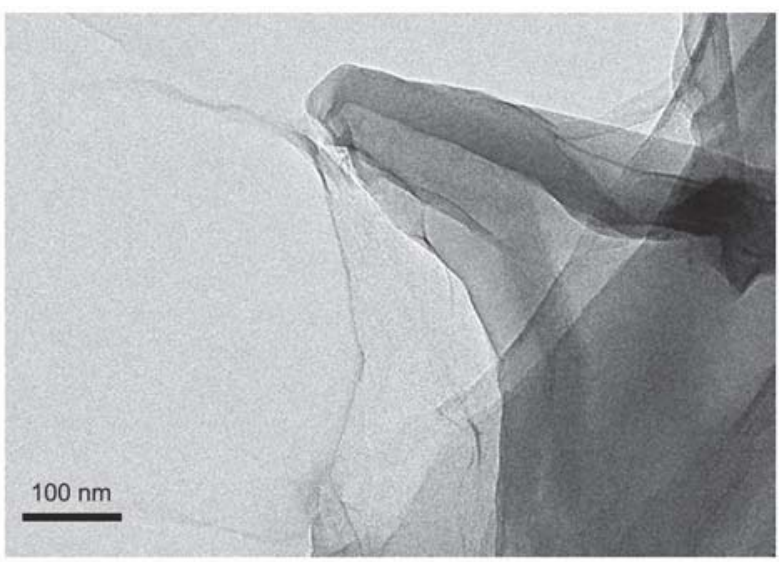

b) 


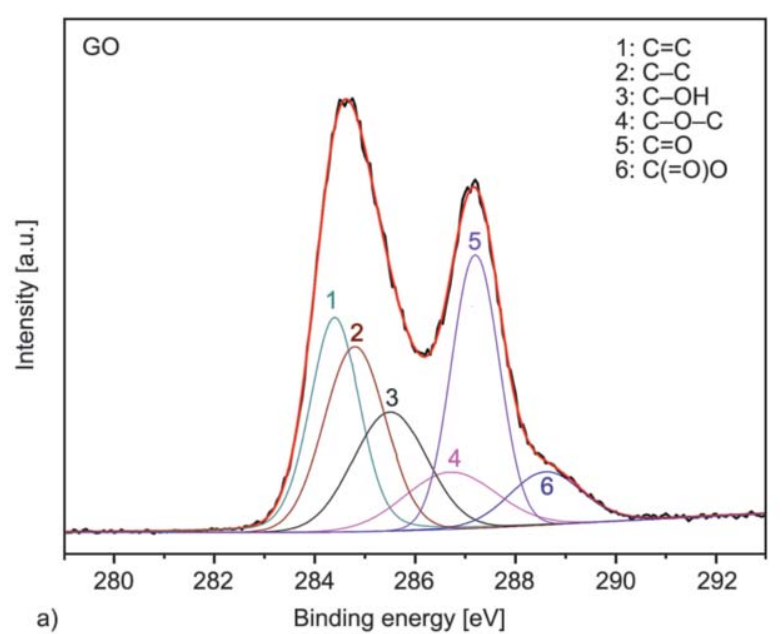

Figure 5. C1s XPS spectra of (a) GO and (b) MAH-GO

Table 1. The chemical compositions of GO and MAH-GO

\begin{tabular}{|l|c|c|c|c|c|c|c|}
\hline \multirow{2}{*}{ Samples } & \multirow{2}{*}{ O/C } & \multicolumn{6}{|c|}{ Contents of chemical groups } \\
\cline { 3 - 8 } & & C=C & C-C & C-OH & C-O-C & C=O & C(=O)O \\
\hline GO & 0.378 & 21.14 & 20.68 & 15.98 & 12.44 & 20.13 & 9.63 \\
\hline MAH-GO & 0.397 & 23.10 & 19.70 & 9.79 & 11.03 & 25.24 & 11.14 \\
\hline
\end{tabular}

XPS is a useful tool in determining the chemical compositions of graphene surfaces. Figure 5 shows the XPS C1s spectra of GO and MAH-GO. It is shown that both of the $\mathrm{C} 1 \mathrm{~s}$ spectra contain six peaks, which are assigned to $\mathrm{C}=\mathrm{C}(284.4 \mathrm{eV}), \mathrm{C}-\mathrm{C}(284.8 \mathrm{eV})$, $\mathrm{C}-\mathrm{OH} \quad(285.6 \mathrm{eV}), \quad \mathrm{C}-\mathrm{O}-\mathrm{C} \quad(286.7 \mathrm{eV}), \quad \mathrm{C}=\mathrm{O}$ $(287.3 \mathrm{eV})$ and $\mathrm{C}(=\mathrm{O}) \mathrm{O}(288.6 \mathrm{eV})$ group, respectively. However, as shown in Table 1, the $\mathrm{O} / \mathrm{C}$ ratio of GO increased slightly from 0.378 to 0.397 after interacting with $\mathrm{MAH}$, which may be caused by the higher oxygen atom concentration in the MAH molecules. Moreover, it is noted that the concentration

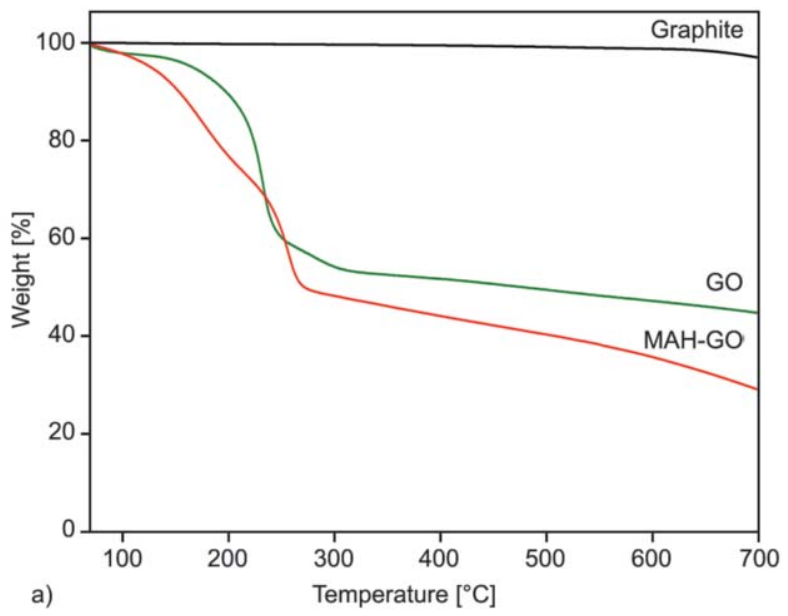

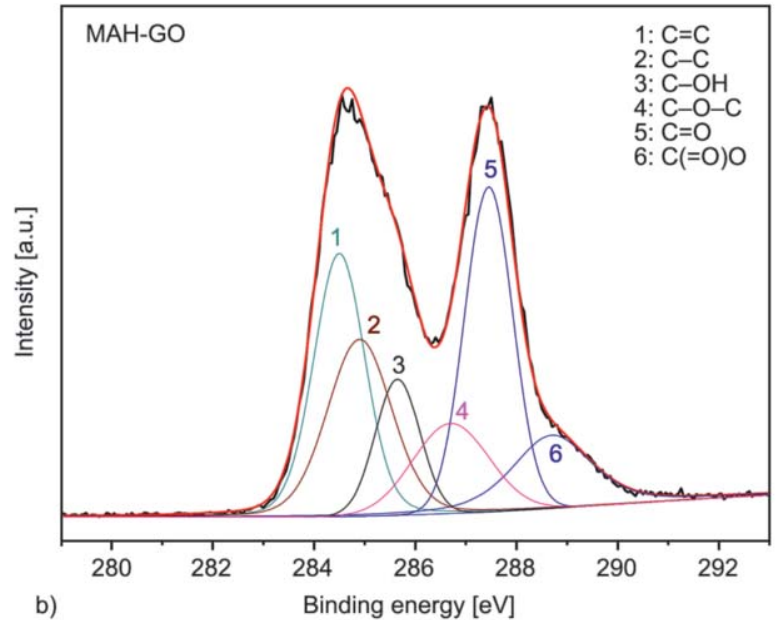

of $\mathrm{C}-\mathrm{OH}$ group decreased from 15.98 to $9.79 \%$, and the concentrations of $\mathrm{C}=\mathrm{O}$ and $\mathrm{C}(=\mathrm{O}) \mathrm{O}$ groups increased from 20.13 to $25.24 \%$ and 9.63 to $11.14 \%$, respectively. The change of these functional group concentrations are caused by the grafting of $\mathrm{MAH}$ molecules onto the GO surface. Meanwhile, it may be concluded that the $\mathrm{C}-\mathrm{OH}$ groups acted as electrophilic groups and reacted with the MAH molecules (see the Figure 1) in the light of the significant decrease of its content.

Figure 6 presents the TGA and DTG curves of graphite, GO and MAH-GO. As can be seen, the pristine graphite is thermally stable. After oxidation, the GO show significant decomposition at approximately $230^{\circ} \mathrm{C}$, which is likely due to the decomposition of labile oxygen-containing functional groups $[9,10$, 20], yielding $\mathrm{CO}, \mathrm{CO}_{2}$ and $\mathrm{H}_{2} \mathrm{O}$. From the DTG curve of MAH-GO, it is clearly shown that there are two weight loss peaks appeared at 176 and $256^{\circ} \mathrm{C}$, re-

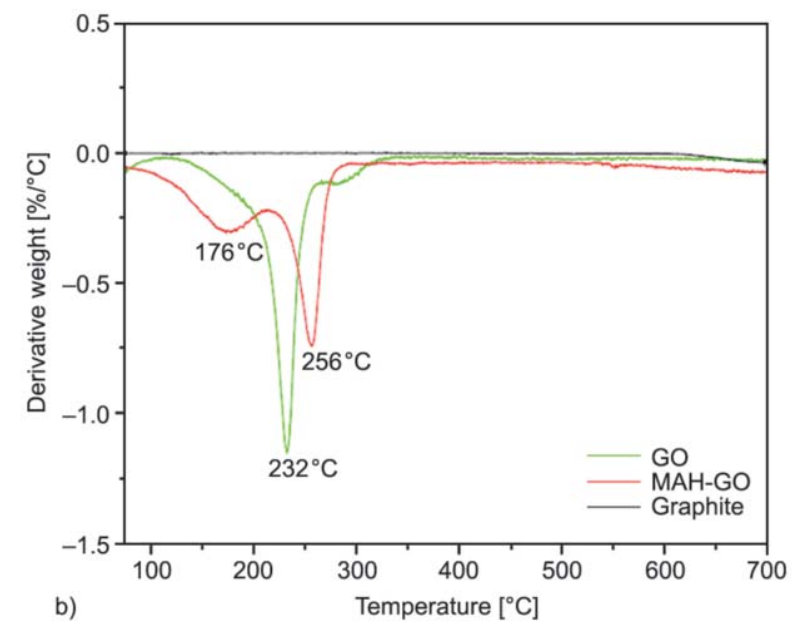

Figure 6. (a) TGA and (b) DTG curves of graphite, GO and MAH-GO 
spectively. This result may be caused by the difference of thermal stability between the grafted MAH molecules and the original labile groups. However, the MAH-GO does not exhibit excessive highly thermal stability, which is explained by the fact that the grafted MAH are also small molecules. By comparison, the weight loss of MAH-GO observed up to $700^{\circ} \mathrm{C}$ (about $71.1 \%$ ) is higher than that of GO (about $55.3 \%$ ), which further alludes to the successful grafting of MAH molecules onto the GO surfaces. The result is consistent with that derived from FT-IR and XPS analysis.

In this study, the aim of covalent functionalization of GO by using MAH is to react the MAH-GO with the BMI resin so as to improve the dispersibility of functionalized GO in the resin matrix. According to the literatures [21, 22], the ene reaction and Diels-Alder reaction have been proposed to be involved in the curing process of BDM and DBA. In view of the high activity of carbon-carbon double bond of grafted MAH, it may be concluded that the MAH-GO could participate in the curing reaction of BMI resin. In order to testify whether the reaction between them occurred or not, the maleic acid was used to react with DBA based on the molecular structure of grafted MAH. Figure 7 shows the FT-IR spectra of maleic acid and DBA before and after reaction.

In the spectrum of maleic acid, the peaks located at 863,1587 and $1705 \mathrm{~cm}^{-1}$ are assigned to the in-plane bending vibration of $\mathrm{C}-\mathrm{H}$ of $\mathrm{CH}=\mathrm{CH}$ group, the stretching vibrations of $\mathrm{C}=\mathrm{C}$ and $\mathrm{C}=\mathrm{O}$, respectively. After react with DBA, the peaks at 1587 and $863 \mathrm{~cm}^{-1}$ are disappeared. This phenomenon indicated that the

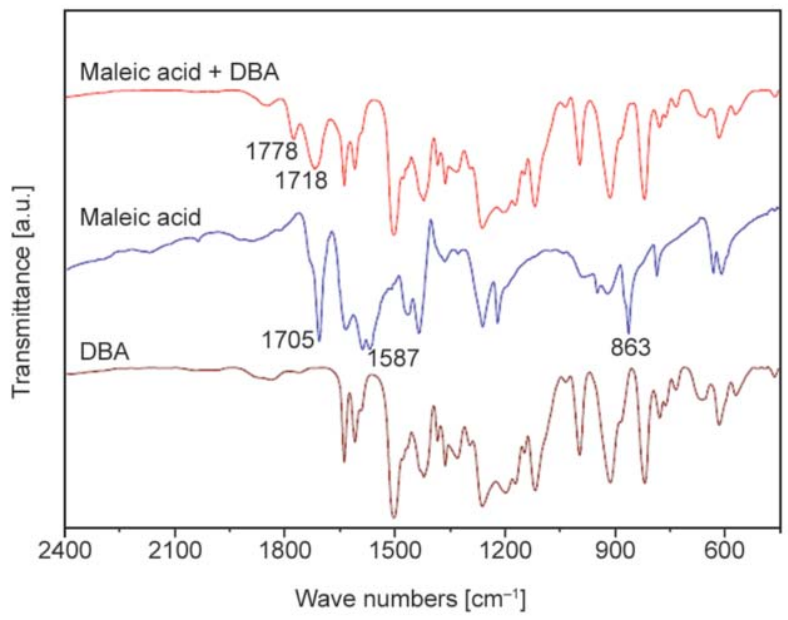

Figure 7. FT-IR spectra of maleic acid and DBA before and after reaction carbon-carbon double bond of maleic acid reacted with the DBA molecules. Therefore, the conjugation effect between the $\mathrm{C}=\mathrm{O}$ and $\mathrm{C}=\mathrm{C}$ was not existed. As a result, the characteristic band of the $\mathrm{C}=\mathrm{O}$ stretching mode of MA split into two peaks (1718 and $1778 \mathrm{~cm}^{-1}$ ). These results confirmed that the MAHGO could take part in the curing reaction of BMI resin.

\subsection{Effect of MAH-GO on the interfacial property of CF/BMI composites}

The ILSS test is an effective method for evaluating the interfacial adhesion property of fiber composites. The effects of GO and MAH-GO on the ILSS of CF/ BMI composites are shown in Figure 8. It is shown that the ILSS of CF/BMI composites increased firstly and then decreased with the increase of filler loading. At $0.1 \mathrm{wt} \%$ loading of GO, the ILSS of composites reached the maximum value of $88.5 \mathrm{MPa}$, corresponding to a slight increase of $5.3 \%$ compared to the $\mathrm{CF} / \mathrm{BMI}$ composite. It is exciting that the maximum improvement of ILSS obtained in the composites containing MAH-GO is far higher than the GO counterparts, which is $24.4 \%$ at $0.15 \mathrm{wt} \%$ loading. The corresponding ILSS value is 104.6 MPa. The result indicted that the interfacial bonding between the carbon fibers and BMI resin was enhanced by the introduction of GO and MAH-GO, and the MAH-GO showed a substantially improved effect.

Although the further increase in the MAH-GO content lead to the decrease of ILSS, which is possibly attributed to the agglomeration of excessive filler, it is still much better than that of the $\mathrm{CF} / \mathrm{BMI}$ compos-

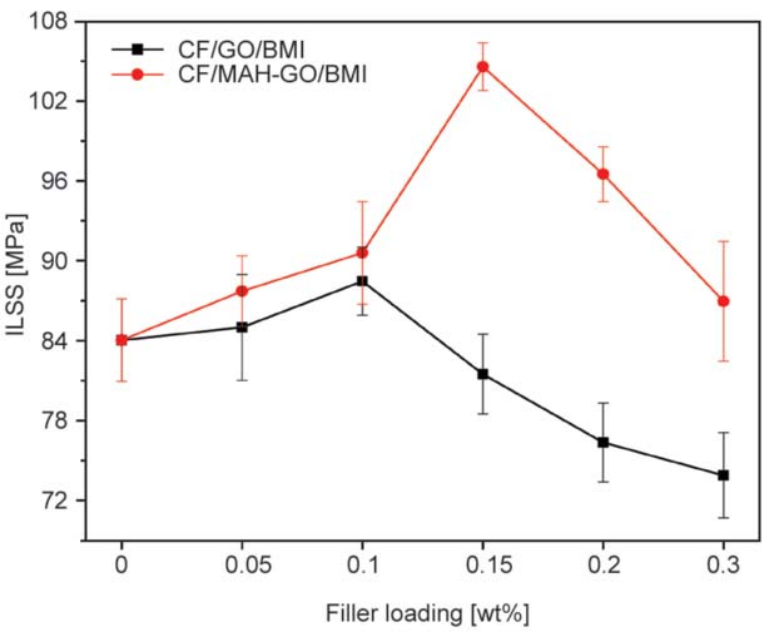

Figure 8. ILSS of neat BMI resin and its composites with different filler loading 
ite. Meanwhile, it is also noted that the ILSS of composites decrease severely when the GO content beyond its optimum value. Based on the above results, it is safe to conclude that the dispersion of MAH-GO in the resin was superior to that of GO due to the chemical interaction between the grafted MAH molecules and the BMI resin. Moreover, the MAH-GO nanosheets bring this advantage into the $\mathrm{CF} / \mathrm{BMI}$ composites to enhance the interfacial adhesion.

To better understand the addition of GO and MAH$\mathrm{GO}$ in enhancing the interfacial adhesion of the $\mathrm{CF} /$ BMI composites, the fracture morphologies of the composites were studied by using SEM, as shown in Figure 9. For the $\mathrm{CF} / \mathrm{BMI}$ composite, quite a number of fibers have smooth surfaces and there is little resin adhered on the surfaces (see the red box in Figure 9a). In addition, it is clearly shown that many CFs are pulled out from the resin matrix and the gaps between CFs and resin are quite large (see the red arrows in Figure 9d). These phenomena indicate that the interfacial adhesion of the $\mathrm{CF} / \mathrm{BMI}$ composite is weak and the fiber debonding occurs easily. When the GO or MAH-GO was introduced into the composite system, the fracture morphologies are obviously different (Figure 9b, 9e and Figure 9c, 9f). Especially for the CF/MAH-GO/BMI composite, the fibers are tightly surrounded by the resin and there are no pulled-out fibers. A large amount of matrix is attached on the CFs surfaces. Moreover, Figure 9g shows that many MAH-GO nanofillers (see the red arrows) are adsorbed on the surface of CFs although few of MAH-GO agglomerates (see the blue arrow) are also existed. Therefore, the interfacial adhesion of composites was improved because more energy was consumed by pulling out the MAH-GO nanofillers from the matrix.

\subsection{Flexural properties of $\mathrm{CF} / \mathrm{BMI}$ composites}

The flexural properties of $\mathrm{CF} / \mathrm{BMI}$ composites were measured and illustrated in Figure 10. The flexural

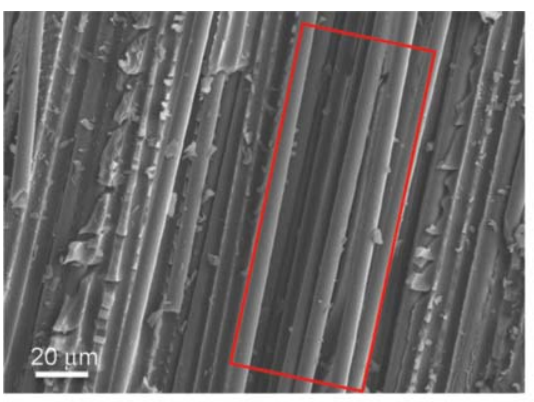

a)

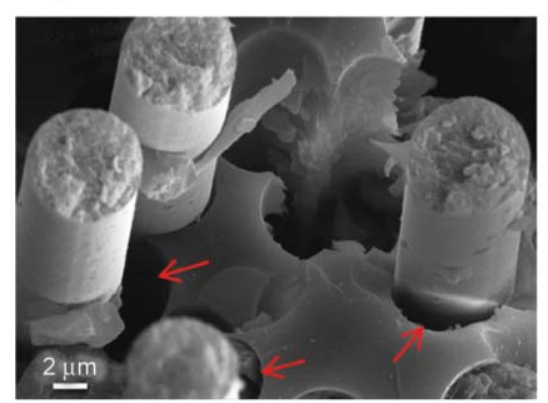

d)

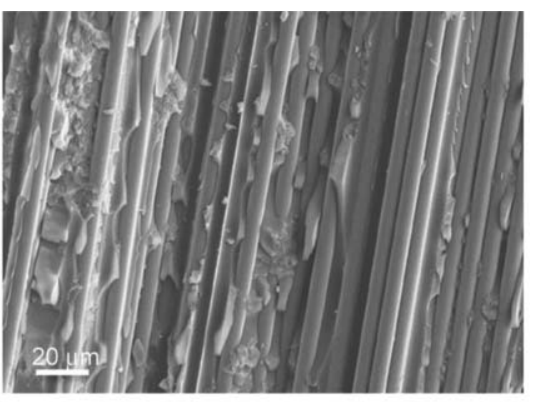

b)

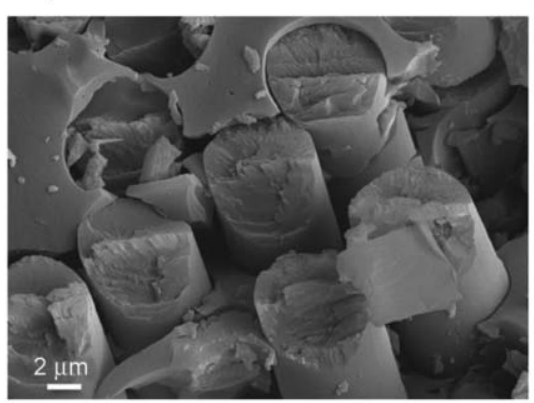

e)
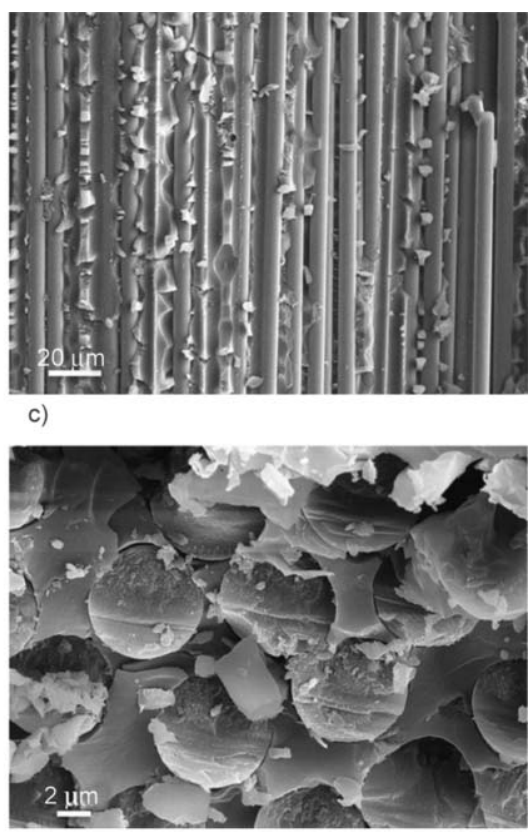

f)

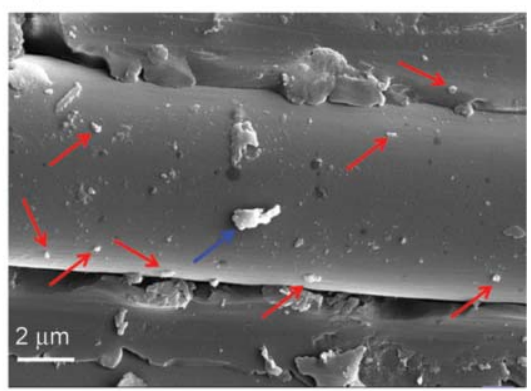

g)

Figure 9. Fracture morphologies of the composites: (a), (d) CF/BMI; (b), (e) CF/BMI with 0.1 wt\% GO; (c), (f), (g) CF/BMI with 0.15 wt $\%$ MAH-GO 
strength for $\mathrm{CF} / \mathrm{BMI}$ composite was $1.36 \mathrm{GPa}$. With the increase of filler loading, the flexural strength increased firstly and then decreased. This tendency is similar to that of the ILSS of the composites. The flexural strength of $\mathrm{CF} / \mathrm{GO} / \mathrm{BMI}$ and $\mathrm{CF} / \mathrm{MAH}-\mathrm{GO} /$ BMI composites reached the maximum values of 1.51 and $1.75 \mathrm{GPa}$ when the GO and MAH-GO content was 0.1 and $0.15 \mathrm{wt} \%, 11.0$ and $28.7 \%$ improvement more than that of the $\mathrm{CF} / \mathrm{BMI}$ composite, respectively.

The improvement of flexural strength should be attributed to the enhancement of the interfacial adhesion between the CFs and MAH-GO (or GO). The enhanced interfacial adhesion allows better load transfer from the resin matrix to the CFs [2, 23]. Another possible reason is the synergistic effects [24] of microscopic CFs and nanoscale MAH-GO (or GO). The CFs and the MAH-GO (or GO) might act as a good combination of reinforcement and to carry the load during the flexural deformation of resin matrix.

Figure $10 \mathrm{~b}$ shows the effects of GO and MAH-GO content on the flexural modulus of CF/BMI composites. It is obviously that the incorporation of GO and MAH-GO yielded an improvement of the composites stiffness and the MAH-GO enhanced the flexural modulus of composites greatly compared with the GO. When the filler content was $0.1 \mathrm{wt} \%$, the flexural modulus of $\mathrm{CF} / \mathrm{GO} / \mathrm{BMI}$ and $\mathrm{CF} / \mathrm{MAH}$ $\mathrm{GO} / \mathrm{BMI}$ composites reached the maxium values of 84.63 and $98.87 \mathrm{GPa}$, which increased 27.9 and $49.7 \%$ with respect to that of CF/BMI composite, respectively. The study also indicates that excessive GO and MAH-GO gave the negative effects to the flexural properties of composites due to the agglom-

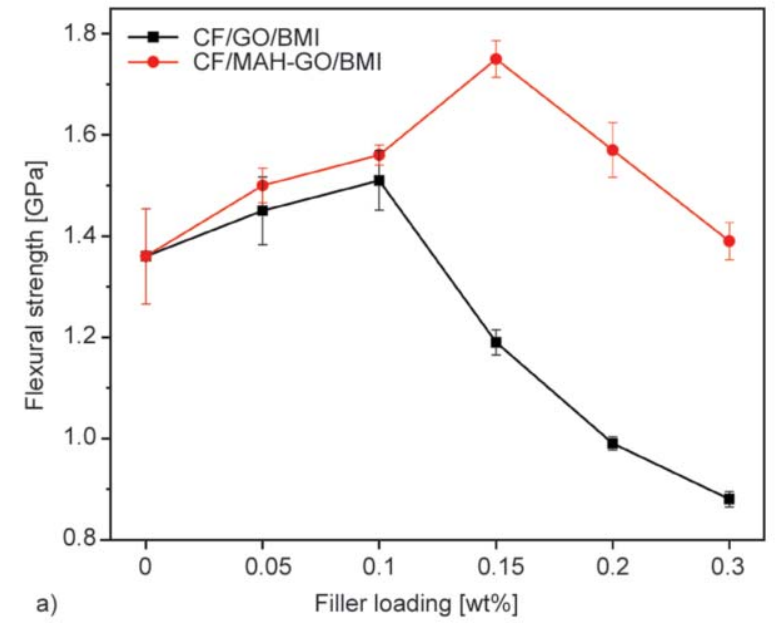

eration. The agglomeration will decrease the surficial contact area of the graphene filler and thus give bad effect in improving the mechanical properties of the $\mathrm{CF}$ composites.

\section{Conclusions}

In this study, we have demonstrated a novel and facile method for improving the interfacial adhesion property of CF/BMI composites. Firstly, the covalent functionalized $\mathrm{GO}$ was synthesized by grafting $\mathrm{MAH}$ onto the GO surfaces. Then, the CF/BMI composites with both the $\mathrm{GO}$ and $\mathrm{MAH}-\mathrm{GO}$ at different loadings were prepared. The effects of GO and MAH-GO on the interfacial adhesion of $\mathrm{CF} / \mathrm{BMI}$ composites were investigated and compared. Due to the high reactivity of carbon-carbon double bond in the grafted MAH molecules, the MAH-GO reacted with the BMI resin during the curing process. This strong chemical interaction between the MAH-GO and the resin matrix gave a substantial increase in the ILSS and flexural properties of $\mathrm{CF} / \mathrm{BMI}$ composite. The enhancement of interfacial adhesion was testified by SEM images of the fracture morphologies.

\section{References}

[1] Zhao F., Huang Y., Liu L., Bai Y., Xu L.: Formation of a carbon fiber/polyhedral oligomeric silsesquioxane/ carbon nanotube hybrid reinforcement and its effect on the interfacial properties of carbon fiber/epoxy composites. Carbon, 49, 2624-2632 (2011). DOI: $10.1016 /$ j.carbon.2011.02.026

[2] Ashori A., Rahmani H., Bahrami R.: Preparation and characterization of functionalized graphene oxide/carbon fiber/epoxy nanocomposites. Polymer Testing, 48, 82-88 (2015).

DOI: $10.1016 / \mathrm{j}$. polymertesting.2015.09.010

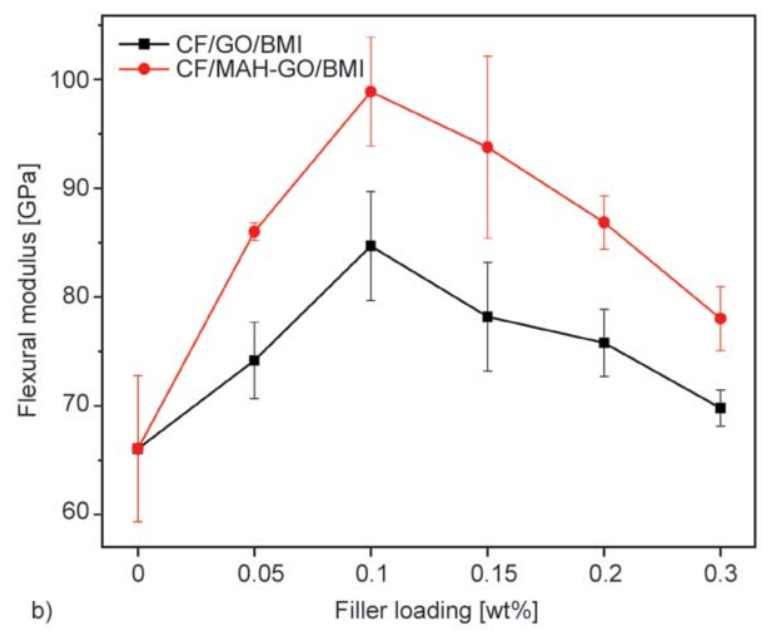

Figure 10. (a) flexural strength and (b) flexural modulus of neat BMI resin and its composites with different filler loading 
[3] Deng S. H., Zhou X. D., Zhu M. Q., Fan C. J., Lin Q. F.: Interfacial toughening and consequent improvement in fracture toughness of carbon fiber reinforced epoxy resin composites: Induced by diblock copolymers. Express Polymer Letters, 7, 925-935 (2013).

DOI: $10.3144 /$ expresspolymlett.2013.90

[4] Li Y., Peng Q., He X., Hu P., Wang C., Shang Y., Wang R., Jiao W., Lv H.: Synthesis and characterization of a new hierarchical reinforcement by chemically grafting graphene oxide onto carbon fibers. Journal of Materials Chemistry, 22, 18748-18752 (2012).

DOI: $10.1039 / \mathrm{c} 2 \mathrm{jm} 32596 \mathrm{a}$

[5] Li W., Yao S. Y., Ma K. M., Chen P.: Effect of plasma modification on the mechanical properties of carbon fiber/phenolphthalein polyaryletherketone composites. Polymer Composites, 34, 368-375 (2013).

DOI: $10.1002 / p c .22385$

[6] Liu L., Jia C., He J., Zhao F., Fan D., Xing L., Wang M., Wang F., Jiang Z., Huang Y.: Interfacial characterization, control and modification of carbon fiber reinforced polymer composites. Composites Science and Technology, 121, 56-72 (2015).

DOI: $10.1016 /$ j.compscitech.2015.08.002

[7] Wu G., Ma L., Wang Y., Liu L., Huang Y.: Interfacial properties and impact toughness of methylphenylsilicone resin composites by chemically grafting POSS and tetraethylenepentamine onto carbon fibers. Composites Part A: Applied Science and Manufacturing, 84, 1-8 (2016).

DOI: 10.1016/j.compositesa.2015.12.015

[8] Fukunaga A., Ueda S.: Anodic surface oxidation for pitch-based carbon fibers and the interfacial bond strengths in epoxy matrices. Composites Science and Technology, 60, 249-254 (2000).

DOI: $10.1016 / \mathrm{S} 0266-3538(99) 00118-9$

[9] Lee C. Y., Bae J-H., Kim T-Y., Chang S-H., Kim S. Y.: Using silane-functionalized graphene oxides for enhancing the interfacial bonding strength of carbon/ epoxy composites. Composites Part A: Applied Science and Manufacturing, 75, 11-17 (2015).

DOI: $10.1016 /$ j.compositesa.2015.04.013

[10] Wan Y-J., Gong L-X., Tang L-C., Wu L-B., Jiang J-X.: Mechanical properties of epoxy composites filled with silane-functionalized graphene oxide. Composites Part A: Applied Science and Manufacturing, 64, 79-89 (2014).

DOI: 10.1016/j.compositesa.2014.04.023

[11] Lim M-Y., Oh J., Kim H. J., Kim K Y., Lee S-S., Lee JC.: Effect of antioxidant grafted graphene oxides on the mechanical and thermal properties of polyketone composites. European Polymer Journal, 69, 156-167 (2015). DOI: 10.1016/j.eurpolymj.2015.06.009

[12] Chatterjee S., Wang J. W., Kuo W. S., Tai N. H., Salzmann C., Li W. L., Hollertz R., Nüesch F. A., Chu B. T. T.: Mechanical reinforcement and thermal conductivity in expanded graphene nanoplatelets reinforced epoxy composites. Chemical Physics Letters, 531, 6-10 (2012). DOI: $10.1016 /$ j.cplett.2012.02.006
[13] Liu M., Duan Y., Wang Y., Zhao Y.: Diazonium functionalization of graphene nanosheets and impact response of aniline modified graphene/bismaleimide nanocomposites. Materials and Design, 53, 466-474 (2014). DOI: $10.1016 /$ j.matdes.2013.07.027

[14] Rozenberg B. A., Dzhavadyan E. A., Morgan R., Shin E.: High-performance bismaleimide matrices: Cure kinetics and mechanism. Polymers for Advanced Technology, 13, 837-844 (2002).

DOI: $10.1002 /$ pat.230

[15] Yan H., Li S., Jia Y., Ma X. Y.: Hyperbranched polysiloxane grafted graphene for improved tribological performance of bismaleimide composites. RSC Advances, 5, 12578-12582 (2015).

DOI: $10.1039 / C 4 R A 13134 G$

[16] Liu C., Yan H., Chen Z., Yuan L., Lv Q.: Effect of surface-functionalized reduced graphene oxide on mechanical and tribological properties of bismaleimide composites. RSC Advances, 5, 46632-46639 (2015). DOI: 10.1039/C5RA06009E

[17] Li W., Zhou B., Wang M., Li Z., Ren R.: Silane functionalization of graphene oxide and its use as a reinforcement in bismaleimide composites. Journal of Materials Science, 50, 5402-5410 (2015).

DOI: $10.1007 / \mathrm{s} 10853-015-9084-\mathrm{Z}$

[18] Hummers Jr. W. S., Offerman R. E.: Preparation of graphitic oxide. Journal of the American Chemical Society, 80, 1339 (1958). DOI: $10.1021 / \mathrm{ja} 01539 \mathrm{a} 017$

[19] Wang X., Xing W., Zhang P., Song L., Yang H., Hua Y.: Covalent functionalization of graphene with organosilane and its use as a reinforcement in epoxy composites. Composites Science and Technology, 72, 737-743 (2012). DOI: 10.1016/j.compscitech.2012.01.027

[20] Yang H., Li F., Shan C., Han D., Zhang Q., Niu L., Ivaska A.: Covalent functionalization of chemically converted graphene sheets via silane and its reinforcement. Journal of Materials Chemistry, 19, 4632-4638 (2009). DOI: $10.1039 / \mathrm{b} 901421 \mathrm{~g}$

[21] Hu X., Meng J.: Effect of organoclay on the curing reactions in bismaleimide/diallyl bisphenol A resin. Journal of Polymer Science Part A: Polymer Chemistry, 43, 994-1006 (2005).

DOI: $10.1002 /$ pola.20521

[22] Li J. J.: Alder ene reaction. in 'Name reactions' (ed.: Li J. J.) Springer, New York, 1-2 (2014). DOI: $10.1007 / 978-3-319-03979-41$

[23] Song K., Zhang Y., Minus M. L.: Polymer interphase self-reinforcement and strengthening mechanisms in low-loaded nanocomposite fibers. Macromolecular Chemistry and Physics, 216, 1313-1320 (2015). DOI: $10.1002 / \mathrm{macp} .201500011$

[24] Pedrazzoli D., Pegoretti A., Kalaitzidou K.: Synergistic effect of exfoliated graphite nanoplatelets and short glass fiber on the mechanical and interfacial properties of epoxy composites. Composites Science and Technology, 98, 15-21 (2014).

DOI: 10.1016/j.compscitech.2014.04.019 